\title{
Reading the Bureaucratic Text: Analysis and Committee Documents
}

\author{
Charles Horn
}

\section{Introduction}

THIS PAPER IS ABOUT ONE FORM of technical writing: the bureaucratic text. $^{1}$ In what follows, I examine in particular a committee document, in this case the "Terms of Reference" from an inter-ministerial committee on Aboriginal social policy. ${ }^{2}$ Drafted principally by an Aboriginal director at the Ministry of Native Affairs, ${ }^{3}$ the document was produced to guide the work of the Committee, tasked in a conventional way with responding to Aboriginal social issues. ${ }^{4}$

As the authors and users of such documents know, there is much to be said about the organizational role of such texts, for instance, in their capacity as administrative instruments for coordinating committees in a public sector bureaucracy. I intend as the analysis proceeds to reveal some of these features of the Committee's "Terms of Reference."

But I am also concerned with the social uses of language, in the way the bureaucratic text articulates, mediates, and shapes broader social interactions, and the role it plays in bureaucratic and other socio-political processes.

My research into the bureaucratic text shows that, in addition to conveying organizational, task-related information (thus fulfilling what Brown and Yule

'Following Enkvist, I take the word "text," to refer to "a meaningful sequence of symbols in a natural language" (1989: 371), grouped in such a way that they possess a "socially ascribed unity" (Hodge and Kress, 1988: 6). A "text" is thus "a larger inscribed cluster of ordered sentences or textual elements in a natural language which possess a socially ascribed unity." See Brown and Yule, 1983; Searle, 1982.

${ }^{2}$ The Committee's formal title is the 'Native Social Policy Working Group', hereafter referred to as 'the Committee'.

${ }^{3}$ While the document, drafted in the fall of 1990, had a principal author it was also the product of a process of collaborative writing, incorporating feedback from both staff in the Ministry and other members of the Committee.

4 In selecting a bureaucratic document as the analysand, one faces an embarrassment of riches; the selection of the Committee "Terms of Reference" from among the thousands of documents available was motivated by a number of factors, including the inter-ministerial nature of the text, and the ready availability of the document to the researcher. 
[1983] have called a "primarily transactional role"), the bureaucratic text is also used by practitioners to constitute, communicate, negotiate, and challenge the social relations that enter into the state apparatus. ${ }^{5}$

In what follows, I show how analyzing the documentary practices of the bureaucracy can give us a glimpse of the inner workings of the state itself: its relationship to its clients, the nature of its internal structure, and the cognitive worlds of its participants. As well, it allows us to see the kinds of entities-objects and subjects-that bureaucratic discourses bring into being. This raises two issues which will serve to focus the remainder of the discussion.

First, it raises the issue of translation: how one moves from the surface features of the text to the underlying social relations and re-casts these in terms accessible to analysts. What is involved in bringing these to light, and what do our efforts reveal? I employ a number of procedures from discourse analysis which prove fruitful in this translation exercise, and I use the Committee's "Terms of Reference" to reveal specific features of the bureaucracy which produced it.

Second, it raises the issue of the effects of employing what I shall call bureaucratic discourses ${ }^{6}$ as a framework, or set of frameworks, through which practitioners interpret the issues and conflicts which are the putative focus of the document and the organization that produced it. What interpretations of the world do these discourses make available and put into circulation, and what actions or actors do such discourses de-legitimate? In this regard, I suggest and later demonstrate that it is the closure of discursive possibilities that those employing bureaucratic discourses effect, not the exploration of

5 I draw from work done by Alford and Friedland (1985) for my analysis of the state, which is located in what these authors call the "managerial perspective." From this perspective, the state is to be analysed according to "the way these organizational structures of power protect themselves from unorganized participation and from the kinds of issues that they cannot manage or control" (p.5). See also Krasner, 1984; Lukes, 1974; Touraine, 1971. I also distinguish between the state and the state apparatus, the former including not only the bureaucracy but also overtly political institutions such as Cabinet, the Legislature, and parties. The latter contains the bureaucratic apparatus.

6 "Discourse," as distinct from "text," refers to the social processes in which texts (or utterances) are embedded and through which they are produced. If text can be understood as the material product of a discourse, then "discourse" can be considered as "text + context" (Brown and Yule, 1983; Enkvist, 1989) and is thus more of a social practice than a set of propositions. 
their openings. Moreover, as an active organizing force, bureaucratic discourses produce effects generally consistent with entrenched and dominant notions of state control, of elite dominance, of the de-politicization of social issues, and of the effacement of agents. ${ }^{7}$ Finally, bureaucratic discourses create, or give ontological effects to, a range of objects and subjects.

\section{Translating the Bureaucratic Text}

Turning now in detail to the first issue: if we wish to analyze the documentary practices of the bureaucracy, what guides our work?

To begin, it would seem appropriate to examine the way in which the social practices and cognitive worlds of the bureaucracy have been textualized, that is, inscribed into documents as a product of organizational discourse.

Bureaucrats themselves generate and use discourses, as I shall show. The bureaucratic text is a site where bureaucratic discourses are realized; it is also where the various discourses that penetrate the state apparatus are mediated and given concrete realization. More importantly, it is the location through which potentially disruptive systems of symbolic representations are contained and the structural and bureaucratic imperatives of the state are re-asserted and, on occasion, re-defined.

Thus, it is plausible to suggest that, under a certain interpretation of a bureaucratic text, we can reveal the underlying social relations of the agents that produce the document and which, in the process of production, leave their traces behind in forms recognizable to the experienced reader (Coulthard, 1977; Giltrow, 1988; Hodge and Kress, 1988; Philips, 1987). It is just such an interpretation that I produce below.

Interpreting or translating ${ }^{8}$ the bureaucratic text I have chosen requires that we pay attention to a number of different levels of meanings (or orders of signification $)^{9}$ which can for analytic purposes be drawn from the text. I touch briefly on three such orders before turning to a direct analysis of the

7 These entrenched and dominant notions cluster together in such a way that it is tempting to see them comprising an "ideology," where that term is used (narrowly) to describe a set of inter-related social meanings which has a distinct function for a social group, and which, in the case of the bureaucracy, is coercively imposed on other social groups. See Hodge and Kress, 1988; Sumner, 1979; Thompson, 1984; cf. Williams, $1976 ; 1977$. 


\section{Committee's "Terms of Reference."}

At one level, the text can be seen as a product of the basic logic and principles by which government institutions operate, what Robert Alford (1975) has called their "structural interests" (e.g., that the state has an interest in social control). Bureaucratic texts are an important means by which such interests are mediated and made available as symbolic representations for circulation and legitimation. both within the state and without.

At another level, the bureaucratic text can be analyzed according to the work it does for bureaucratic practitioners, who interpret the writings of their workplace according to those background beliefs and understandings they possess in virtue of their status as bureaucrats.

Finally, the technical writing of the bureaucracy can be read as discourse, which involves noting the ways in which the underlying characteristics of the state (its ideologies, the forces, and struggles it contains), as well as the bureaucrat's working knowledge, are presented in the surface structure and syntax of the text. It's a reading of the document in terms of the fundamental social relations which structure its outward demeanour. But, as discourse, the bureaucratic text does not merely reflect (in some direct and unproblematic manner) the social practices which give rise to it. In addition, the bureaucratic text, as discourse, is also a system of statements that constructs its object, or, as is more often the case, an inter-related set of objects (Parker, 1992). ${ }^{10}$ The discursive level of analysis deals with the explicit content of the text, but it does so to explore both the other levels of signification and the extra-textual realities that they reflect, and the ways in which the text constructs its own objects.

8 See David Murray, (1991), for an interesting discussion of some of the wider issues of translation and the textual representation of Aboriginal peoples. See also Talal Asad, (1986), "The concept of cultural translation in British social anthropology," in Clifford and Marcus (1986).

9 On the question of orders of signification, see Roland Barthes' 1972 work, Mythologies or his earlier work (1968), Elements of Semiology. See also John Fiske and John Hartley, (1978), Reading Television.

"The use of the word "reflect" here raises the difficuit question of the precise relationship between any particular text and the non-textual or non-discursive realms in which the text is located. On this point, see Murray, 1991, and Raymond Williams, (1977), Marxism and Literature. 


\section{Committee Terms of Reference as Discourse}

These issues can be illustrated and some further points developed by turning now to the text selected for analysis, the "Terms of Reference" document, reproduced in the Appendix. In what follows, I examine the ways in which particular meanings are constructed and attached to specific material signifiers present in the document and thereby realized as discourse.

The first thing to notice about the document is that it is a document: a formal written text as opposed to a conversation, or even a transcript of an oral exchange. It is perhaps true, as Walter Ong reminds us, that both conversational exchanges and bureaucratic documents are "technological products of a chirographic society," and so constitute written modes of expression, the two modes having both been profoundly shaped by the historical shift from orality to literacy (Ong, 1982). But it is also true that the text under consideration is the product of an institution-the provincial government-whose practices are essentially document based. While terms of reference may be discussed orally and are in fact often extensively altered as a result of conversational exchanges, they require documentary form to effectively accomplish their social role (in contrast, for instance, with urban myths, whose social life relies upon oral exchanges). ${ }^{11}$ And in the bureaucracy, documents are dominant with regard to substantive decision making; in administration, the conventional hierarchy between oral and written forms of knowledge is sharpened, with written products having significantly more institutional value than oral exchanges.

Formal written documents are a type of text not often described in recent discussions of discourse analysis. ${ }^{12}$ Recent discourse analysis, more influenced by ethnography and sociology, has placed less emphasis on the written text and has instead focused on conversations, rich as they are in opportunities for such things as repair sequences, turn-taking, topic initiation and control, and clarification indices, features which have proven fruitful in analyzing the social relations and interpersonal dynamics underlying conversations (e.g., Schegloff, 1968; Schegloff and Sacks, 1973; Schiffrin, 1977).

"Conversations within bureaucracies (and elsewhere) might constitute what James Clifford calls "oral domains within a dominant literacy" (1988: 340).

12 Early linguistic research in this area demonstrated significant syntactic, lexical, and grammatical differences between the two modalities, without, however, implying a difference as to research suitability. See Redecker, (1984), for an overview and discussion of this research. 
I argue that it is, ironically, the very richness attributed to the oral by conversational analysts that precludes it from occupying a privileged place in the social relations present in the state apparatus. For the written text plays such a prominent role in the bureaucracy precisely because its alternativethe oral-is much more difficult to control; the open-endedness of conversations, even those with mutual goals, leads to a greater range of discursive procedures (topic control, error repair, etc.) and to less predictable outcomes (Brown and Yule, 1983; Coulthard, 1981). While this is fruitful for discourse analysts, it is precisely this unpredictability and open-endedness that state managers wish to avoid, for in general it is the closure of discursive possibilities that the state seeks, not the exploration of their openings.

In contrast to the oral, the written text presents those who would control the state and its apparatus with at least one level of discursive (and thus they hope, political) control; the surface structure (syntax, grammar, vocabulary) of the bureaucratic document. This text is both a reflection of relations among agents and a lever to control and organize the interpretation of reality available to those agents, in part because the act of thematizing certain objects and valorizing certain kinds of subjects is also the creation, or in many cases the reproduction, of a social ontology.

The document-based nature of bureaucratic discourse gives us our first clue as to the way in which the state and state apparatus work. The written text is much more closely controlled; it is subject to significantly greater external review; it can be planned, edited, re-written, and revised.

Without yet turning to the specific content of the document, we can see that bureaucratic discourse is in fact a highly channelled, highly conventional discourse. Translating the bureaucratic text, then, starts with an understanding of its formal, written nature.

With regards to its specific content, the Committee's "Terms of Reference" displays a range of typographical features which organize the document into discrete sections. For the purpose of the analysis, I have divided the document into 23 elements, and analysed a number of them in detail (see Appendix). ${ }^{13}$

Items 1 and 2 in the reproduced document ostensibly label the document and give direction to its content and administrative function. As a signifying practice, these two lines set up an insider/insider understanding, activating a shared schema and signalling to participants that what follows both has a ge-

13 Numerical markings on the left margins of the reproduced document are there for reference and are not part of the original. 
neric form and is designed for internal bureaucratic use.

The phrase, "working group," in Item 1 can be analysed at the practitioner level-the order of signification which is realised via the nonuniversal background knowledge of readers/writers. This phrase parsimoniously draws a line of inclusion and exclusion, largely by accessing participants' shared knowledge that "working groups" are internal affairs and hence do not involve, for instance, managing public opinion.

The more complex phrase, "Native Social Policy Working Group" also indicates that the author of the text is an institutional authority; the voice is that of an organizational entity with the jurisdiction to structure a number of bureaucratic discourses into a unified text, or a coherent series of utterances which can be circulated within the administration. As a characteristic signifier of the bureaucracy, the noun phrase "working group" marks the need to continually gloss the dispersal of power, the constant erosion and fragmentation of meaning under which the signs of the state operate. The words name the space for a unity, a 'working group,' whose existence is predicated on creating a coherence, on reigning in a dispersion, on bringing together and binding a diverse group of state practices and agencies. So the phrase also marks an activity, the continued active effort by governing institutions to prevent fragmentation and disunity, on the one hand, and to promote coordination and strengthen internal chains of command, on the other.

Item 2 indicates a well established situational regularity, that of a committee of government, and a formal regularity: in this situation-the formation of a working group-the appropriate response is to draft terms of reference. These lines initiate the reader into a larger set of rules (or, in Hodge and Kresses' terms, a logonomic system [1988:5]) and situate the text as part of an established genre. The presence of formal and situational regularities (a genre) enables participants to recognize typical definitions of situations and respond in mutually acceptable ways (Miller, 1984; Giltrow, 1988; Hodge and Kress, 1988)..

One larger set of rules (which could be said to comprise a part of the ideology of state agents) is that which establishes the legitimacy of the state to create and institutionalize social policy for Aboriginal peoples; a sub-set of these rules allows the process to occur among state managers in the absence of any non-state actors. There is a hierarchy of power implicit here, which locates the subject of the document-Aboriginal peoples-in a subordinate role to the reader/producer with respect to certain areas of decision making. I shall 
return to this last point further on as it coheres locally with other points in the text and globally with the objectives of the text producers.

The section entitled 'Affirmation of Mandate' is significant for the glimpse it gives of the relationship between authority and knowledge in the state apparatus and of the way in which the state responds to external pressures. Consider, for instance, the first four lines of the 'Affirmation of Mandate' section (Items 3-6). One of the claims of discourse analysis is that, given a social system characterized by power differentials, participants in a discursive situation must be capable of recognizing and using linguistic registers and speech acts that reflect the rights and obligations of that system of social stratification (Hodge and Kress, 1988). The first four lines of the "Affirmation" section articulate precisely such a social (bureaucratic) stratification, by making highly visible in the document the ownership of the issue and the Ministry's asserted (and at another level, assigned) right to its interpretation and resolution. The use of the phrase, "provide leadership on behalf of," in Item 5 is a rhetorical manoeuvre to establish ("provide leadership") and ground ("on behalf of") a social relation of asymmetrical power between state agencies. At the level of bureaucratic practice, these items signify the Ministry's claim to a position of functional dominance. Finally, Item 6, which speaks to "policy development," sets out the Ministry's claimed right to guide strategic choices and the micropolitical direction of the state in the area.

These four lines of text display some interesting features. While not much documentary ground has been covered, a great deal of semiotic work has been done: in these opening moves a ground is established, the outline of a formal hierarchy is signified, and its legitimacy is affirmed. These opening lines indicate to the participants that the situation is one which involves relations of power and authority: at the practitioner level the signifiers, "provide leadership" and "assure inter-ministry coordination," are associated in the cognitive world of the bureaucrat with possessing or relinquishing positions of authority or control over a program of action.

As well, the phrase "Ministry of Native Affairs" (in Item 4) signals the presence of institutional borders within the state, marking out as discrete an entity whose principal business is "Native Affairs." The words set out a border and at the same time authorize the activity of policing it. The signifying practices which leave their mark in the document are intimately concerned with the inscription and re-iteration of boundaries, boundaries which act as a vehicle through which realms of subjects and objects are constituted, reproduced, organized, and disciplined. 
At the structural level, these textual elements signify the existence of a social group (Aboriginal peoples) subordinated to the political and bureaucratic structures of non-Aboriginal society, for it is worth noting that it is an agency of government, not Aboriginal people per se that "provides leadership." The domination is not yet complete, however; the signifier, "in cooperation with," implies the presence of resistance by Aboriginal peoples, a resistance which cannot be completely elided. Indeed, the rhetorical goal of the Ministry is to ensure that the conflict between Aboriginal peoples and non-Aboriginals is not denied but rather that it become institutionalised and thereby resolved. Indeed, one of the things the text does is to constitute, or help to constitute, a subject-position called "Aboriginal peoples," which provides a focus around which the activities of the Ministry can circulate, be made meaningful, and reproduce themselves.

If we turn now to the question of coherence, Item 7, "assure coordination," is of interest (in part) for the weakness of its local coherence (an incoherence attenuated by the use of point form). It is not obvious what pattern of inference licenses the move from "develop policy" (Item 6) to "assure inter-ministry coordination" (Item 7). Why is it that these two elements are contiguous on the page, and both subsumed under the same rubric? If the text is 'rational' in some Gricean sense of that word, then the breakdown of coherence should be in appearance only. While it is not entirely clear what would resolve the apparent (local) incoherence, the frequency of locutions like "assure coordination" in bureaucratic texts suggests that the schema for most committee documents ${ }^{14}$ contains "coordination" syntagms ${ }^{15}$ as a generic entry. It may be that its presence is a generic requirement, but that its placement in the text at that particular point is relatively arbitrary.

Despite weak or uncertain local coherence, Item 7 displays strong global coherence, especially in the item's relatively opaque role as part of a transactive/ administrative document, in that it coheres with one long-term objective of most large, internally complex organizations: internal efficiency. This reflects the concern with the number of transactions that are required to process people and issues; the emphasis on coordination arises from the need to internalize these transactions and thereby govern them more closely.

At a more opaque level, it signifies a central aspect of bureaucratic ideol-

14 Meeting minutes might be an exception.

15 Hodge and Kress define a syntagm as a "significant combination of signs in spacetime" (1988: 262). 
ogy: the univocity of the state. The struggles and negotiations for power among various social groups are allowed to appear only indirectly, if at all, at the surface of state discourse. Indeed, they are represented discursively in Items 3 through 9 as necessary and appropriate administrative and technical practices entailed by the existence of the organization in its present form, which is presented as unproblematic in the discourse.

This results, in part, from the need to keep the confidence of the dominant faction of the political/bureaucratic elite who control the state and, to a lesser degree, its apparatus, and who are ultimately the audience and consumers of bureaucratic texts. Signals of univocity in the text indicate that there is cohesion among the state's constituent parts, accomplished in part by collapsing indicators of social difference and particularity into a globalizing management discourse. The discourse of coordination also acts as an incantation against the dispersal of power and meaning which beset the signifying practices of the state. It's an invocation of unity in the face of multiplicity.

The effects of this are manifold. In part, the imperative to univocity functions to hide the political nature of the state apparatus and thus reduces its saliency as a point of struggle for dominated groups. No point of difference is offered which could be exploited by groups antagonistic to the existing arrangements. As well, the usefulness of the discursive element, "assure coordination," for exercising social control over the internal workforce is incorporated productively.

Items 8 and 9-"liaise with Indian groups" and "recommend policy" (to the political level)-assert linkages and points of access between the Ministry and relevant stakeholders.

Item 8 asserts to experienced bureaucratic practitioners the Ministry's access to Aboriginal groups and local communities, and signifies its knowledge of other relevant bureaucracies. The initial phrase of Item 8 "liaise with Indian groups, [and] local communities"-is interesting, for it signifies, at the level of discourse, a rhetorical acceptance of democratic norms, which stipulate that the state apparatus ought to be open to participation and directives from non-state agents ("the people"), and not just to political elites. Analysed at the structural level, this "liaising" has social control functions: it provides bureaucratic and political elites with the necessary information to blunt the development of crises of legitimacy and breakdowns in domination and hegemony.

Item 9 articulates a linkage, not of access, but of power and authority, 
reiterating the organizational hierarchy and the Working Group's and the Ministry's place in it. Noting the reporting relationship to decision-making centres functions administratively to create or enforce a common understanding of decision-making procedures and channels; more covertly, at the practitioner level, it authorizes and buttresses the prior leadership claims (and is thus locally as well as globally coherent).

Item 10, outlining Ministry goals, is of interest in its attempt to maintain local coherence (viz. the phrase, "in keeping with") while accomplishing a thematic shift. The previous items were about licensing the occupation of a field of action; items 10 through 14 describe the ends to which it will be put.

Item 11 , for instance, assures that-in the best tradition of an occupying force-the state power held by the Ministry will be put to the expected end: "good working relationships" will be established and Aboriginal dissent muted. The sequence of signifiers here draws its signification from elements of liberal (technocratic) state-management ideology, in which the appropriate response to social dislocation and resistance is more sophisticated state intervention and incorporation into the ideological state apparatus, that is, "better services and more sensitive programs".

But as item 13-remarking on Native self-government initiativesshows, the belief that the state can be used to advance Aboriginal social, economic, and cultural goals is in tension with the underlying recognition motivating the document, namely, that the state has so far been incapable of doing precisely this. The global plan of the Committee and thus of the document is to resolve this tension. Item 13 is typical of the way in which this failure has been interpreted and captured in discourse: it denotes at the structural order of signification that addressing the issue strictly through the governing structures of the dominant society has met with little success and significant resistance. The resolution promised in the text involves some territorial concessions by the state mixed with an (often rhetorical) commitment to modifying state practices in response to critiques from Aboriginal political and administrative elites. Nevertheless, some paternalistic ideological elements remain, through the implication that the government can "assist" Aboriginal peoples.

Finally, some comments about Items 15 through 22, which outline the purposes and tasks of the Working Group, are in order. It is interesting to note that only at Item 15, quite far into the text, is the purpose of the group itself (the ostensive topic of the document) addressed. Consistent with earlier items, the purpose is thematized as one of coordination, but, again consistent with 
earlier items in the document, the work of the Group is presented as subordinate to the mandate of the Ministry.

This feature displays what Enkvist calls "textual iconicism," in which the arrangement of the text stands for non-textual experience (1981). This can be seen in the way that control over strategic resources in the field of bureaucratic social relations (the non-textual experience) is iconic with the physical dominance of the Ministry's mandate evident throughout much of the first page of the text.

A final relevant point is brought out by the repetition of the word "identify" in Items 18-22. The use of the term "identify" here points to the existence of rules which govern how messages are to be received and produced as a logonomic system. The use of the word, "identify," follows from a particular set of these rules operative in the bureaucracy which prescribe as appropriate and necessary the action of classification, of an analytic rendering of the social world into manipulable parts, the dynamics of which can be administered by bureaucratic divisions. It is the element of classification and articulation of populations that Foucault wrote of as being central to a normalizing power (Foucault, 1972).

Thus the use of this locution signifies one of the state's primary concerns, which is not to understand but to delineate, locate, specify, and, under appropriate conditions, dominate. As such, this norm is one specification of the relation of knowledge to power. The purposes, indeed, the very forms of knowing, are directed to the controlling imperatives of the state, while its surface construction is designed to obscure that practice. As such, this norm is one element of the ideology of the bureaucracy (in the limited and specific sense of the term, "ideology," used here). It also evidences the bureaucratic ideology of technocratic problem solving.

These last items (15-22), then, bring out the rhetorical strategies and discursive elements in the text which act, in a semiotic sense, to embody social relations: on the one hand by a kind of textual iconicism, as in the dominant role assigned the Ministry's mandate, and on the other by implicitly referencing the compartmentalizing norm which structures bureaucratic relations. In this way the social relations of the bureaucracy are realized in discourse. 


\section{Power and Knowledge in Bureaucratic Settings}

The previous points have brought out how, in the bureaucratic setting, the written text plays an important role in providing knowledgeable participants with a set of social messages. While some of these messages are available at the surface of the text (e.g., factual statements about committee structure and chains of command), others are more opaque, involving a different order of signification and requiring a discursive or social analysis to bring them into view. These latter messages condition the possible readings of the signifieds in the document and act, for instance, to construct meanings about the division of labour among agencies and to locate participants in the specific hierarchy associated with that division.

It is by virtue of specific textual elements (format, schema-invoking headings, the use of certain phrases) that these messages are activated or understood by experienced readers and producers. These readers/producers bring to the task specific, non-universal rules and assumptions, some of which pertain to the particular setting and some which can be considered elements of a bureaucratic ideology. In this interpretation process, certain authorities are assured, further communicative acts are licensed, and a set of relations is constituted as "appropriate" or "necessary."

One such relation deserves further comment: the relation between power and knowledge. We saw earlier how various textual strategies were used to establish the scope of the Ministry's mandate, the social terrain within which it is licensed to act. But these strategies themselves operate in, or perhaps as, a peculiar economy, through which circulates power on the one hand, and knowledge on the other. The social capital in this economy is the authority to wield power, in that the bureaucracy possesses institutional legitimacy, at least among the non-Aboriginal population, which is operationalized through the ability to make and enforce decisions-allocative, punitive, and otherwise. The Ministry seeks to accumulate and use this capital, now in one arena, now in another, keeping some liquid and some fixed.

The unit of exchange for the Ministry is knowledge, for the Ministry possesses relevant knowledge of the social, cultural, economic, and political practices and aspirations of a group whose claims threaten the economic base and the moral legitimacy of the state. The text under analysis is a response to those claims, a response that is couched in two different but related discourses: the discourse of expertise and the discourse of institutional authority.

Sometimes the two discourses are contained in the same sign: Item 6, for 
instance ("developing policy related to Native issues"), contains both a claim to institutional authority and a claim to expertise; the one claim bolsters and legitimates the other, although semiotically they may operate at different levels of signification.

The text operates at multiple levels, then: at the level of establishing administrative and bureaucratic procedures; at the level of creating and circulating discourses of coordination and policy development, of expertise and institutional authority; and at the level in which various social forces and those who claim to represent them in the state struggle, negotiate, and extract concessions between and among themselves.

While the document considered here is tied to a particular committee, and thus has a certain autonomy from other documents, the more general level at which it operates implies that it has necessary links to other government texts. Some of these links arise because of shared generic elements, and some by a process of documentary diffusion, as a second document (such as a cabinet submission) may be constructed with elements drawn from the first. But it is the nature of a discourse that it is realized, not in one or another text, but in a cluster of related texts, which give the discourse its material form and allow its signifieds to be circulated and re-iterated (Parker, 1992). As such the document does not operate alone but as a member of a loosely defined gang; as a carrier of a number of (sometimes competing) discourses the bureaucratic text lives a promiscuous social life, associating now with one document, now with another, depending on the discourses to be reproduced and circulated.

As a site for the realization of discourse, the text also produces objects and subjects. In this case, the bureaucratic discourses demarcated above work to produce, for example, "Native people," "Native issues," "selfgovernment," "problems." But these discursive objects are rendered in such a way that space is also made available for other, related objects and subjects to step in and be given voice. So in addition, the document that we have been analyzing constructs (or reproduces), as a kind of response to the above entities, "the Ministry of Native Affairs," "the Provincial government," "coordinating mechanisms," "the Native Social Policy Working Group," and other related entities. As I have tried to show, the construction and deployment of these discursive entities has the general effect of reproducing and legitimating existing structures of power and bureaucratic domination. Sometimes these effects are resisted and the traces of that resistance can also be found in the text.

The text chosen for discussion reveals the state, and the bureaucratic text itself, as a site for struggle and negotiation, in which the state attempts to 
maintain its commitment to discursive hegemony in the face of the challenges presented to its practices by a population marginalized by the dominant society: Native North Americans. As the specific subjectivity against and through which the text constructs itself, Aboriginal peoples present a point of rupture, breakdown, and attempted re-unification as far as the systems of bureaucratic order are concerned. The analysis also brings out the ways in which the signifying practices of the state are deployed, reiterated, and institutionalized, so as to constitute, specify and authorize a series of entities and institutional acts. An examination of other future relevant texts, I predict, will show that the policy and administrative changes required by changes in Aboriginal/state relations would be accompanied by changes in discursive signification.

\section{Conclusion}

Throughout this paper I have been interested in exploring the bureaucratic use of language. I have argued that the written material of the bureaucracy can be understood as a means by which complex social messages about state power, cultural knowledge, and the norms and ideology of the state apparatus are transmitted, negotiated, and reproduced or rejected. The social reality of the state apparatus, I have implied, is one of struggle between the competing agencies for power, a struggle in which, in this case at least, knowledge of a particular kind is instrumental in the attempt to control an arena of decision-making. While these struggles are contained in the state, in their turn they reflect the conflicts and alliances among and between elements in the dominant society and dominated groups.

At one level of signification-that of the practitioner-the surface features of the text, the signifieds, convey an overlapping but distinct set of messages about the relations among social groups, state agencies, and civil society. These are available to the experienced participant and are accessed by means of nonuniversal background assumptions possessed by the producers and receivers of the text. I have attempted to bring some of these significations and assumptions to light.

But the analysis is not simply an examination of the cognitive world of individual bureaucrats, for that knowledge and those social relations are made available for strategic use within the state apparatus by being attached to a cluster of trans-individual bureaucratic discourses and vested in the entities and relations those discourses license. In the process of constituting a social reality through which social action can be controlled, these underlying ten- 
sions and struggles, in particular the resistance of Aboriginal peoples to political and racial domination, are muted, de-politicized, and rendered compatible with state practices and ideologies.

One implication of my research has been that an adequate theory of the state must account for the way in which these social forces and power differentials are internalized and represented in the state apparatus and how that internalization and related signifying practices represent ways of muting or de-politicizing possible challenges to the state's authority and legitimacy. I have focused on the ways in which this is attempted discursively; other analyses are possible, even necessary.

Finally, my research reveals that the textualization of the social relations and practices that enter into the state can also be read in a way that reveals the ideology of the bureaucracy and the ways in which the protection of the dominant from the challenges of the dominated structures the micro-political activities of bureaucrats. As can be seen in the preceding analysis, while these are analytically useful, they are not always easy to distinguish in practice. Further research into the discursive practices of the state can perhaps contribute to such readings of bureaucratic texts.

\section{Appendix}

\section{Native Social Policy Working Group: Terms of Reference}

\section{NATIVE SOCIAL POLICY WORKING GROUP}

2. TERMS OF REFERENCE

\section{AFFIRMATION OF MANDATE}

4. The mandate of the Ministry of Native Affairs is to:

5. * provide leadership on behalf of the provincial government in cooperating with Native people in pursuit of their social, economic and cultural goals;

6. * develop policy related to various Native issues

7. * assure inter-ministry coordination of program issues; 
8. * liaise with Indian groups, local communities and the federal government on Native issues, and;

9. * coordinate, communicate, and recommend policy to the Premier's Council on Native Affairs and the Cabinet committee on Native Affairs.

10. In keeping with the mandate of providing leadership on behalf of the provincial government, the Ministry's main goals are to:

11. * form good working relationships between Native people and the provincial government;

12. * encourage and support social and economic development for Native people;

13. * assist Native Bands, tribal councils or groups proposing selfgovernment initiatives; and

14. * help solve problems between Native people and the provincial government.

15. PURPOSE OF NATIVE SOCIAL POLICY WORKING GROUP

16. In order for the Ministry of Native Affairs to carry out its mandate of assuring interministry coordination of program issues, a working group comprised of the social policy ministries has been organized to develop a Native social policy framework for a provincial government strategy.

17. The specific tasks of the working group are to:

18. * identify current and planned initiatives as they relate to Native people;

19. * identify emerging issues related to Native people which will affect Provincial Government policy and program planning;

20. * identify policy and program planning areas which require further coordination, information sharing, and decision making for policy development;

21. * identify needs and anticipated program support requirements, alternatives, and options for addressing service gaps and/or overlaps; and

22. * identify federal/provincial jurisdictional issues, responsibilities, and expectations. 


\section{STRUCTURE}

The working group chaired by the Ministry of Native Affairs comprises senior level representation from the following ministries:

Advanced Education, Training and Technology

Labour and Consumer Services

Social Services and Housing

Solicitor General

Attorney General

Municipal Affairs, Recreation and Culture

Health

Education

Women's Programs

\section{TENURE}

The term of the working group is to meet as often as required to accomplish the objectives established in the terms of reference by March 3, 1990. The draft Native Social Policy Framework will be presented to the Assistant Deputy Ministers Steering Committee for their consideration.

\section{WORKPLAN}

It is anticipated that the Native Social Policy Working Group will draft a proposed workplan with an appropriate schedule for accomplishing specific tasks defined in the terms of reference.

\section{References}

Adler, J., and Adler, R. (1987). Field Roles in Membership Research. Sage University Paper Series on Qualitative Research Methods, Volume 3. Beverley Hills, CA.: Sage. 
Agar, M. and Hobbs, J. (1982). Interpreting Discourse: Coherence and the Analysis of Ethnographic Interviews. In Discourse Processes. Vol. 5, 132.

Agar, M. (1986). Speaking of Ethnography. Sage University Paper Series on Qualitative Research Methods, Volume 2. Beverly Hills, CA.: Sage.

Ajzenstadt, M. and Giltrow, J. (1988). Understanding the Text of Prohibition: Discourse Analysis as a Means of Exploring Community Membership. Paper presented at the Annual Meeting of the American Society of Criminology, Chicago, IL., November 10, 1988.

Alford, R. (1975). Paradigms of Relations Between State and Society. In L.N. Lindberg, R. Alford, C. Cronch and C. Offe, Stress Contradictions in Modern Capitalism. Lexington, MA.: Lexington Books.

Alford, R., and Friedland, R. (1985). Powers of Theory: Capitalism. the State and Democracy. Cambridge: Cambridge University Press.

Asad, Talal. (1986). The Concept of Cultural Translation in British Social Anthropology. In James Clifford and George Marcus (Eds.) Writing Culture: the Poetics and Politics of Ethnography. Berkeley, CA.: University of California Press.

Barthes, R. (1977). Image-Music-Text. London: Fontana.

Barthes, R. (1972). Mythologies. Trans. Annette Lavers. New York, NY.: Hill and Wang.

Barthes, R. (1968). Elements of Semiology. London: Paladin Press.

Bonjour, L. (1985). The Structure of Empirical Knowledge. Cambridge, MA.: Harvard University Press.

Brown, G., and Yule, G. (1983). Discourse Analysis. Cambridge, MA.: Cambridge University Press. 
Burton, F., and Carlen, P. (1979). Official Discourse: on Discourse Analysis, Government Publications, Ideology and the State. London: Routledge \& Kegan Paul.

Choon-kyu Oh. (1989) (Ed). Presupposition. New York, NY.: Academic Press.

Cicourel. A.V. (1987). Cognitive and Organizational Aspects of Medical

Diagnostic Reasoning. In Discourse Processes. Vol. 10. No. 4, 347-367.

Clifford, J., and Marcus, G.E. (1986). Writing Culture: The Poetics and Politics of Ethnography. Berkeley and Los Angeles, CA.: University of California Press.

Clifford, J. (1988). The Predicament of Culture: Twentieth-century Ethnography, Literature and Art. Cambridge, MA.: Harvard University Press.

Collins, J. (1987). Conversation and Knowledge in Bureaucratic Settings. Discourse Processes.Vol.10, No. 4, 291-303.

Coulthard, M. (1977). An Introduction to Discourse Analysis. Harlow, Essex: Longman.

Coultard, M. (1981). Developing a Description of Spoken Discourse. Studies In Discourse Analysis. Malcolm Coulthard and Martin Montgomery (Eds). London: Routledge \& Kegan Paul.

Eco, U. (1972). Towards a Semiotic Inquiry Into the TV Message. WPCS, No. 3, 103-121.

Edelman, M. (1984). The Political Language of the Helping Professions. Language and Politics. Michael J. Shapiro (Ed). London: Basil Blackwell, 44-61.

Enkvist, N.E. (1989). From Text to Interpretability: A Contribution to the Discussion of Basic Terms in Text Linguistics. Connexity and Coherence: Analysis of Text and Discourse. Wolfgang Heydrich, Fritz Neubauer, Janos S. Petofi and Emel Sozer (Eds). Berlin: Walter de Gruter.

Enkvist, N.E. (1981). Experiential Iconicism in Text Strategy. Text.l, 97-111.

Ferguson, K. (1983). Feminism and Bureaucratic Discourse. New Political Science, No. 11, Spring.

Fiske, J., and Hartley, J. (1978). Reading Television. London: Metheun. 
Foucault, M. (1972). The Archaeology of Knowledge. Tr. A.M. Sheridan Smith. London: Tavistock.

Fowler, et al. (1979). Language and Control. London: Routledge \& Kegan Paul.

Freeman, S.H. (1987). Organizational Constraints as Communicative Variables in Bureaucratic Medical Settings. Discourse Processes. Vol. 10, No. 4 , 385-400.

Gallie, W.B. (1968). Philosophy and the Historical Understanding. Second Ed., New York, NY.: Schocken Books.

Garfinkle, H. (1967). Studies in Ethnomethodology. Englewood Cliffs, NJ.: Prentice-Hall.

Geertz, C. (1975). The Interpretation of Cultures. London: Hutchinson Press.

Giltrow, J. (1988). Canadian Contexts for Public Advocacy: Briefs as Genre. Paper presented at the Annual Meeting of the Canadian Association of Teachers of Technical Writing. Windsor, Ontario, May 30, 1988.

Giddens, A. (1979). Central Problems in Social Theory: Action. Structure, and Contradiction in Social Analysis. Berkeley, CA..: University of California Press.

Giddens, A. (1984). The Constitution of Society: Outlines of a Theory of Structuration. Cambridge, MA.: Polity Press.

Gouldner, A.W. (1976). The Dialectic of Ideology and Technology: the Origins, Grammar, and Future of Ideology. London: MacMillan.

Grice, H.P. (1985). Logic and Conversation. In A.P. Martinich (Ed), The Philosophy Of Language. New York, NY.: Oxford University Press, 159170.

Gumperz, J. (1968). The Speech Community. International Encyclopedia of the Social Sciences. London: MacMillan, 381-386.

Gumperz, J. (1982). Discourse Strategies. New York: Cambridge University Press.

Hodge, R., and Kress, G. (1988). Social Semiotics. Ithaca, NY.: Cornell University Press. 
Hodge, R. and Kress, G. (1979). Language as Ideology. London: Routledge and Kegan Paul.

Keller-Cohen, D. (1987). Organizational Contexts and Texts: the Redesign of the Midwest Bell Telephone Bill. Discourse Processes. Vol. 10, No. 4 . pp. 417-428.

Krasner, S. (1984). Approaches to the State: Alternative Conceptions and Historical Dynamics. Comparative Politics. 16, 223-246.

Kress, G., and Trew, A.A. (1978). Ideological Transformation of Discourse: or How the Sunday Times Got Its Message Across. Sociological Review, 26, $755-76$.

Levinson, S.C. (1983). Pragmatics. Cambridge, MA.: Cambridge University Press.

Lukes, S. (1974), Power: A Radical View. London: MacMillan.

Miller, C. (1984). Genre as Social Action. Quarterly Journal of Speech, 70, $151-167$.

Murray, D. (1991). Forked Tongues: Speech, Writing and Representation in North American Indian Texts. Bloomington, IN.: Indiana University Press.

Ong. W.J. (1982). Orality and Literacy: The Technologizing of the Word. London: Metheun and Company.

Parker, I. (1992). Discourse Dynamics: Critical Analysis for Social and Individual Psychology. London: Routledge.

Penman, R. (1987). Discourse in Courts: Cooperation, Coercion, and Coherence. Discourse Processes, Vol.10, No.4, 201-218.

Philips, S.U. (1987). The Social Organization of Knowledge and its Consequences for Discourse in Bureaucratic Settings. Discourse Processes. Vol.10. No.4, 201-218.

Redecker, G. (1984). On Differences Between Spoken and Written Language. Discourse Processes. 7, 43-55.

Ricoeur, P. (1978). The Rule of Metaphor: Multi-disciplinary Studies of the Creation of Meaning in Language. London: Routledge and Kegan Paul. 
Saville-Troike, M. (1989). The Ethnography of Communication. London: Basil Blackwell.

Schegloff, E. (1968). Sequencing in Conversational Openings. American Anthropologist. 70, (6), 1075-1095.

Schegloff, E. and Sacks, H. (1973). Opening Up Closings. Semiotica. 8, 289327.

Schiffrin, D. (1977). Opening Encounters. American Sociological Review. 42 , (5), 679-691.

Searle, J. (1982). What is a Speech Act? In Pier Paolo Giglioli (Ed). Language and Social Context. Middlesex: Penguin Books, 136-154.

Sperber, D. and Wilson, D. (1986). Relevance: Communication and Cognition. Cambridge, MA.: Harvard University Press.

Sumner, C. (1979). Reading Ideologies: An Investigation into the Marxist Theory of Ideology and Law. London: Academic Press.

Thompson, J.B. (1984). Studies in the Theory of Ideology. Berkeley, CA.: University of California Press.

Touraine, A. (1971). The Post-industrial Society-Tomorrow's Social History: Class, Conflicts and Culture in the Programmed Society. New York, NY.: Random House.

Touraine, A. (1977). The Self Production of Society. Chicago, IL.: University of Chicago Press.

Williams, R. (1976). Keywords. London: Fontana.

Williams, R. (1977). Marxism and Literature. Oxford: Oxford University Press. 
